\title{
Failure of Flow Diverter Treatment of Intracranial Aneurysms Related to the Fetal-type Posterior Communicating Artery
}

\author{
Anderson Chun On Tsang, M.B.B.S.'*, Arthur Man Yuen Fung, M.B.B.S.'*, \\ Frederick Chun Pong Tsang, M.B.B.S.', Gilberto Ka Kit Leung, M.S.', \\ Raymand Lee, M.B.B.S. ${ }^{2}$, Wai Man Lui, M.B.B.S.'
}

Purpose: The pipeline embolization device (PED) is a flow diverter that has shown promise in the treatment of intracranial aneurysms. Close to one-fifth of aneurysms, however, fail to occlude after PED placement. This study aims to identify anatomical features and clinicopathologic factors that may predispose failed aneurysm occlusion with the PED.

Materials and Methods: We retrospectively reviewed all anterior circulation unruptured saccular aneurysms treated with the PED in a single-center. The primary outcome measure was angiographic occlusion. Anatomical features and potential predictors, including gender, aneurysm location, size, height, aspect ratio, neck width, prior treatment and the number of PED, were studied using binary logistic regression.

Results: 29 anterior circulation unruptured saccular aneurysms with a mean size of $6.99 \mathrm{~mm}$ treated with the PED in a single center were retrospectively studied. The overall occlusion rate was $79.3 \%$ after a mean follow-up of 9.2 months. Four aneurysms were related to the fetal-type posterior communicating artery (PComA), and all were refractory to flow diverter treatment. Female gender was significantly associated with a higher occlusion rate. We present the anatomical features and propose possible pathophysiological mechanisms of these PComA aneurysms that failed flow diverter treatment.

Conclusion: A PComA aneurysm with persistent fetal-type circulation appears to be particularly refractory to flow diverter treatment, especially when the aneurysm incorporates a significant portion of the PComA. Our experience suggested that flow diverting stents alone may not be the ideal treat-

'Division of Neurosurgery, Department of Surgery, Li Ka Shing Faculty of Medicine, The University of Hong Kong, Queen Mary Hospital, Hong Kong; ${ }^{2}$ Department of Radiology, Queen Mary Hospital, Hong Kong

Received February 24, 2015;

accepted after revision June 1, 2015.

Correspondence to: Dr. Anderson C.O. Tsang, Division of Neurosurgery, Department of Surgery, Li Ka Shing Faculty of Medicine, The University of Hong Kong, Queen Mary Hospital, 102 Pokfulam Road, Hong Kong.

Tel. 852.2255.3368 Fax. 852.2818.4350 E-mail: acotsang@hku.hk

This is an Open Access article distributed under the terms of the Creative Commons Attribution Non-Commercial License (http://creativecommons.org/licenses/by-nc/3.0) which permits unrestricted non-commercial use, distribution, and reproduction in any medium, provided the original work is properly cited. 
ment for this subgroup of aneurysms, and alternative modalities should be considered. Female patients were found to have a significantly higher rate of treatment success.

Key Words : Fetal circulation; Flow diverters; Intracranial aneurysm; Outcome; Pipeline embolization device

The pipeline embolization device (PED) is a flow diverter that has shown promise in the treatment of unruptured intracranial aneurysms (IAs) that are not readily amenable to conventional therapies such as coiling or clipping. It acts by decreasing inflow to an IA, thereby causing thrombosis within the aneurysm sac [1-3]. In a recent systematic review, the PED was found to achieve an occlusion rate of $83 \%$ at 6 -months, with an overall mortality and a peri-procedural complication rate of $2.2 \%$ and $6.3 \%$, respectively [4]. Nonetheless, close to one-fifth of the IAs treated with the PED would not occlude, and information on predictors of flow diverter failure is lacking. In this study, we aimed at identifying potential predictors of treatment outcome on saccular IAs in the anterior circulation, with a particular focus on the anatomical characteristics related to flow diverter failures.

\section{MATERIALS AND METHODS}

\section{Patients}

This is a retrospective study of consecutive patients with saccular unruptured IAs in the anterior circulation that were treated with the PED (Covidien Vascular Therapies, Mansfield, MA, USA) from September 2008 to December 2011. Posterior circulation, fusiform and dissecting IAs were excluded. Of the 29 patients identified, 24 were female. The mean age was 57.2 (range 35-80). 26 of the patients had been included in a previous study that reported on 178 IAs treated at seven neurosurgical centers in this locality [5]. This earlier report, however, did not include risk factor analysis for treatment failure, which would be the focus of the present study.

\section{Endovascular procedure}

Patients received oral clopidogrel ( $75 \mathrm{mg} /$ day) and aspirin $(100 \mathrm{mg} /$ day $)$ for three days before PED placement. Clopidogrel and aspirin were continued after surgery for at least three and six months, respectively. PED placement followed the standard guideline under general anesthesia through a transfemoral route [3]. Systemic heparinization was used. Adjuvant coiling and additional PED placement were used at the discretion of the interventionists when there was significant persistent contrast-filling within the aneurysm sac. Follow-up imaging studies with computerized tomography angiography (CTA), magnetic resonance angiography (MRA) or digital subtraction angiogram (DSA) were performed at 6- and 18-months. Successful flow diverter treatment was defined as total exclusion of the aneurysm from the circulation with no residual neck on angiogram.

\section{Data analysis}

The primary outcome measure was angiographic IA occlusion. Secondary outcome measures included periprocedural complications, such as ischemic infarction, transient ischemic attack (TIA), intracerebral hemorrhage (ICH) as well as stent migration or thrombosis. We analyzed the following potential predictors for treatment failure: gender, IA location, size (the largest dome diameter), height, aspect ratio (the ratio of aneurysm height to neck width) [6], wideneck lesions (defined as neck width $>4 \mathrm{~mm}$ ), prior endovascular treatment, and the number of PED used. These variables were studied using binary logistic regression against IA occlusion with SPSS software (version 20, IBM, New York, USA). A p-value of less than 0.05 was considered statistically significant.

\section{RESULTS}

\section{Aneurysm characteristics}

There were 29 patients with 29 IAs. Table 1 shows their characteristics. There were 23 small and six large IAs, with a mean size of $6.99 \mathrm{~mm}$ (range: 2.1 to 22 $\mathrm{mm})$. Wide-neck IAs accounted for $48.2 \%(\mathrm{n}=14)$, and $55.1 \%(n=16)$ of the IAs had an aspect ratio of less than 1.5. Four IAs arose from the fetal-type posterior communicating artery (PComA) origin, three from other segments of the supraclinoid internal carotid artery (ICA), five from the cavernous ICA and 17 from the paraclinoid ICA. One IA had previous stentassisted coiling, while three others received previous coiling only. 


\section{PED treatment outcomes}

The PED was successfully deployed in all cases. Out of 29 aneurysms, six did not occlude, yielding an overall occlusion rate of $79.3 \%(n=23)$. These included all four IAs that were arising at the PComA origin with persistent fetal-type circulations. Curve reformation angiography showed that the residual aneurysm necks in these lesions were all incorporating a portion of the fetal-type PComA after PED placement. Representative cases and anatomical features were illustrated in the following section.

Nineteen IAs received one PED, and the remaining 10 received two devices each. Two IAs required adjuvant coiling. The mean follow-up duration was 270 days (range: 150 to 800). Lower occlusion rates were found with wide-neck lesions $(64.2 \%)$, IAs with aspect ratios of $\leq 1.5(75.0 \%)$, and those with prior treatment $(50 \%)$, but these did not reach statistical significance. Only gender was found to have a significant correlation, female patients had a higher occlusion rate compared to men $(87.5 \%$ vs. $40 \%, p=0.033)$ (Table $2)$. There was no mortality. The overall symptomatic complication rate was $10.3 \%(\mathrm{n}=3)$, including two TIAs. One patient suffered from left frontal parenchy-

Table 1. Clinicopathologic Features and Outcome of the 29 Aneurysms Treated with the Pipeline Embolization Device

\begin{tabular}{|c|c|}
\hline Size (mm) & Mean: 6.99 Range: $2.1-22$ \\
\hline \multicolumn{2}{|l|}{ Size by group } \\
\hline Small $(<10 \mathrm{~mm})$ & 23 \\
\hline Large (10-25 mm) & 6 \\
\hline \multicolumn{2}{|l|}{ Neck width } \\
\hline$\leq 4 \mathrm{~mm}$ & 16 \\
\hline$>4 \mathrm{~mm}$ & 13 \\
\hline \multicolumn{2}{|l|}{ Aspect ratio } \\
\hline$\leq 1.5$ & 16 \\
\hline$>1.5$ & 13 \\
\hline \multicolumn{2}{|l|}{ Prior treatment } \\
\hline None & 25 \\
\hline Stenting + coiling & 1 \\
\hline Coiling & 3 \\
\hline \multicolumn{2}{|l|}{ Number of PED used } \\
\hline One & 19 \\
\hline Two & 10 \\
\hline Use of adjuvant coiling & 2 \\
\hline
\end{tabular}

mal hemorrhage one day after operation, secondary to rupture of an underlying arterio-venous malformation, which was an incidental finding. Craniotomy and clot evacuation were performed, and he subsequently recovered to functional independence (modified Rankin Scale 2).

\section{Illustrative cases}

\section{Patient 1}

A 60 -year-old woman had a $7.6 \mathrm{~mm}$ wide-neck right PComA IA. It received feeding from both the ICA and the fetal-type PComA (Fig. 1A). One PED was placed initially, but the aneurysm received persistent inflow from the fetal-type PComA. A second PED was placed 15 months later. Follow-up angiography showed a persistent aneurysm despite flow diverters at 18 months after the second PED (Fig. 1B).

\section{Patient 2}

A 73-year-old man had a $4.4 \mathrm{~mm}$ right PComA lesion

Table 2. Binary Logistic Regression Analysis of Potential Predictors for Failed Aneurysm Occlusion

\begin{tabular}{|c|c|c|c|c|}
\hline Factors & Subgroups & $\begin{array}{l}\text { Occluded / } \\
\text { Total no. IA }\end{array}$ & $\begin{array}{l}\text { Occlusion } \\
\text { rate }\end{array}$ & P-value \\
\hline \multirow[t]{2}{*}{ Gender } & Men & $2 / 5$ & $40 \%$ & 0.033 \\
\hline & Women & $21 / 24$ & $87.5 \%$ & \\
\hline \multirow[t]{4}{*}{ IA location } & PComA & $0 / 4$ & $0 \%$ & 0.999 \\
\hline & Cavernous ICA & $4 / 5$ & $80 \%$ & \\
\hline & Paraclinoid ICA & $17 / 17$ & $100 \%$ & \\
\hline & Supraclinoid ICA & $2 / 3$ & $66.7 \%$ & \\
\hline \multirow[t]{2}{*}{ Size* } & Small & $19 / 23$ & $82.6 \%$ & 0.145 \\
\hline & Large & $4 / 6$ & $66.7 \%$ & \\
\hline \multirow[t]{2}{*}{ Aspect ratio } & $\leq 1.5$ & $12 / 16$ & $75.0 \%$ & 0.528 \\
\hline & $>1.5$ & $11 / 13$ & $84.6 \%$ & \\
\hline \multirow[t]{2}{*}{ Neck width } & $\leq 4 \mathrm{~mm}$ & $14 / 15$ & $93.3 \%$ & 0.081 \\
\hline & $>4 \mathrm{~mm}$ & $9 / 14$ & $64.2 \%$ & \\
\hline \multirow[t]{2}{*}{ Prior treatment } & None & $21 / 25$ & $84 \%$ & 0.145 \\
\hline & Prior treatment & $2 / 4$ & $50 \%$ & \\
\hline \multirow[t]{2}{*}{ No. of PED used } & One & $17 / 19$ & $89.5 \%$ & 0.079 \\
\hline & Two & $6 / 10$ & $60 \%$ & \\
\hline
\end{tabular}

${ }^{*}$ Size: small $(<10 \mathrm{~mm})$, large $(10-25 \mathrm{~mm})$.

+ Other than PComA lesions.

IA, Intracranial aneurysm; PComA, posterior communicating artery; ICA, internal carotid artery 
that reconstituted after initial coil embolization. CTA and DSA again showed the presence of persistent fetaltype circulation, and the IA was fed by both the ICA and the PComA (Fig. 2A, B). Two PEDs were placed. MRA performed 12 and 24 months later showed a static residual aneurysm neck.

\section{Patient 3}

A 68-year-old man had an $11 \mathrm{~mm}$ left PComA lesion supplied from both the ICA and the fetal-type PComA
(Fig. 3A, B). There was reconstitution despite three sessions of coil embolization, the last being stentassisted. One PED was placed across the aneurysm in 2011. Follow-up DSA six months afterwards showed residual filling of the aneurysm. (Fig. 3C)

\section{DISCUSSION}

The PED was approved by the United States Food and Drug Administration (FDA) in 2011 for the
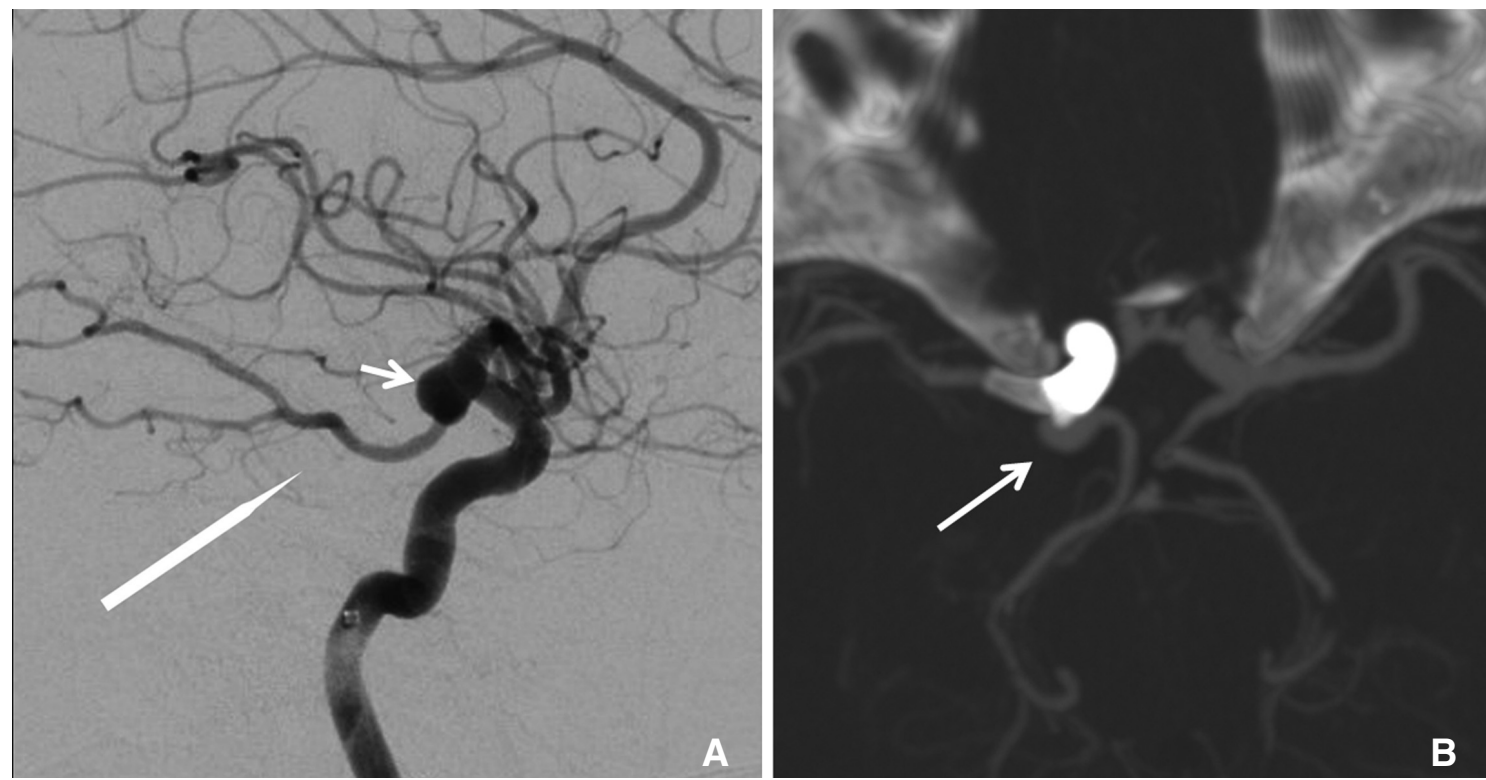

Fig. 1. Patient 1. (A) Pre-treatment digital subtraction angiography showing the fetal-type posterior communicating artery circulation (long arrow) and aneurysm (arrow); (B) curve reformation of the post-treatment CTA showed that the right PComA IA was receiving persistent supply from the fetal PComA (arrow).
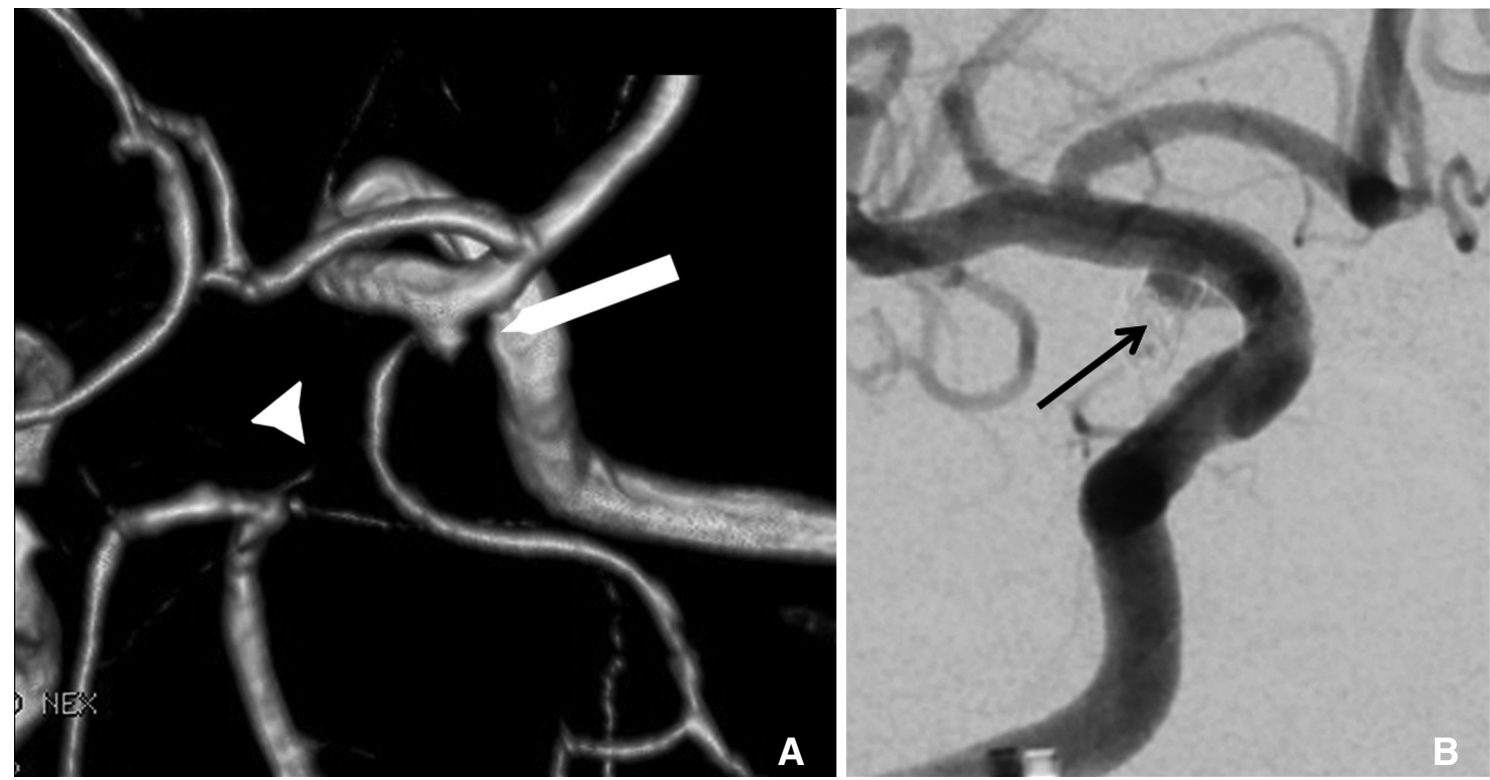

Fig. 2. Patient 2. (A) Pre-treatment computer tomography angiography showing the right posterior communicating artery (PComA) aneurysm remnant (long arrow), which was previously treated with four GDC coils, and the atrophic right P1 segment (arrowhead) associated with fetal-type; (B) control DSA showing persistent supply to the aneurysm despite coverage with PED (black arrow). 
treatment of a selected group of anterior circulation IAs. A multi-center study involving 178 IAs treated in our locality reported occlusion rates of $81 \%$ at 12 months, and $84 \%$ at 18 months [5]. These results were consistent with other reports in the literature [4, 7-9]. Currently, only a limited number of studies have investigated predisposing factors for incomplete occlusion after PED placement. O'Kelly et al analyzed 97 unruptured IAs and performed multivariate analysis for predictors. The female gender $(\mathrm{OR}=0.52, \mathrm{p}=$ $0.03)$ and prior treatment $(\mathrm{OR}=0.36, \mathrm{p}=0.002)$ were associated with lower success rates [9]. In McAuliffe's series of 57 IAs, those with prior treatments also had a lower occlusion rate at 6 months. Those without prior treatment attained an occlusion rate of $92.5 \%$, compared with $80 \%$ in those previously treated with coiling or clipping, and $50 \%$ in those with previous stenting or stent-assisted coiling [7]. The authors postulated that the presence of a prior stent may compromise the apposition of the PED to the arterial wall, thus creating endoleak and persistent filling of the aneurysm. We found a similar trend, though it did not reach statistical significance possibly due to the small number of patients with prior treatments in our cohort.

Notably, we found that fetal-type PComA IAs were associated with a particularly poor occlusion rate in our series. All of our PComA IA had fetal type circulation, and none achieved occlusion. PComA IAs are the second most common aneurysms overall, accounting for $25 \%$ of all IAs and $50 \%$ of all ICA IAs [10]. The most common type is the one in which the neck of the IA originates from the ICA and partially incorporates the PComA. Rarely, the neck of the IA may originate solely from the PComA [10]. A PComA with persistent
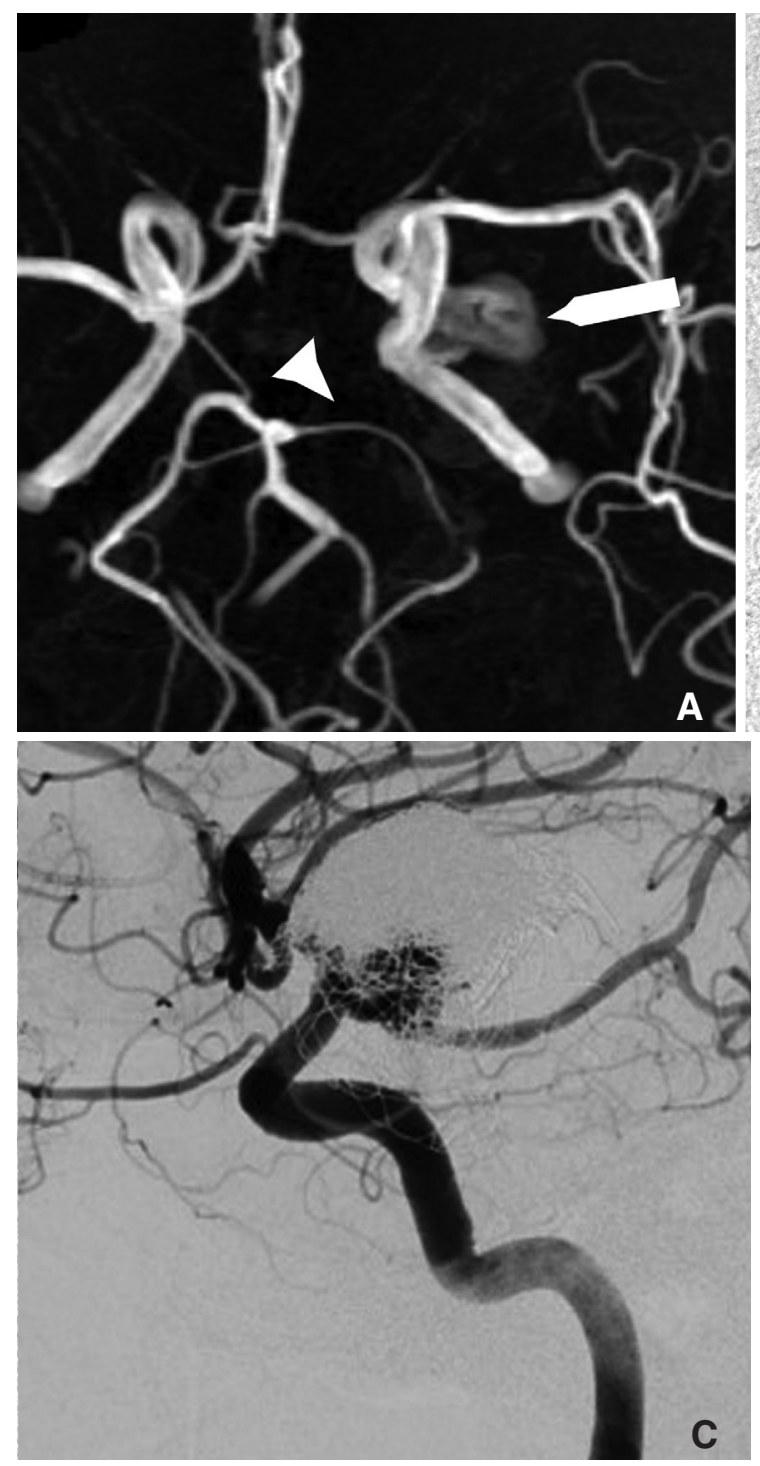

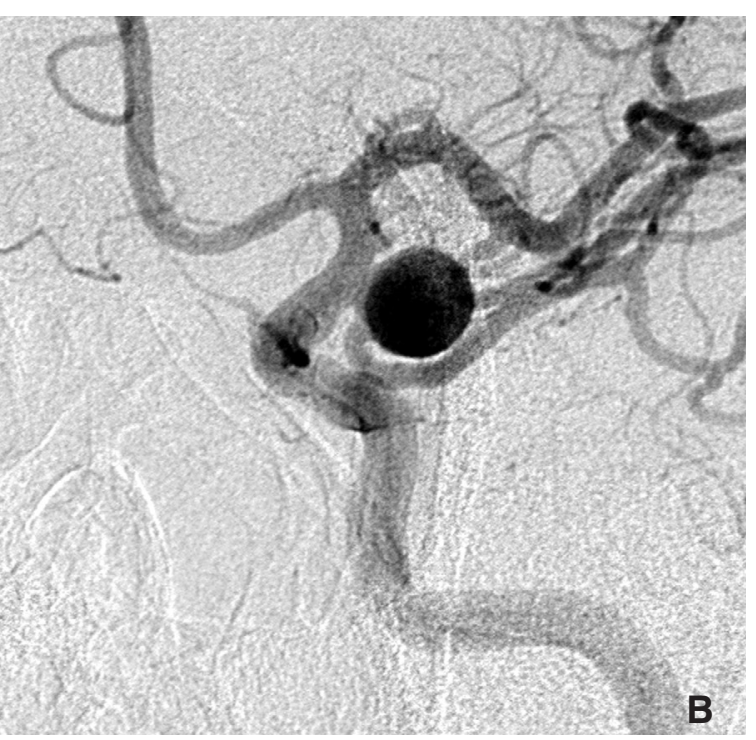

Fig. 3. Patient 3. (A) Pre-treatment magnetic resonance angiography showing the left-sided aneurysm (long arrow), and the atrophic right $\mathrm{P} 1$ segment (arrow head) associated with fetal-type circulation; (B) pre-treatment digital subtraction angiography showing that the aneurysm received supply from both the internal carotid artery and the fetal posterior communicating artery; (C) digital subtraction angiography performed six months after the placement of one pipeline device showing persistent contrast filling of the slightly enlarged aneurysm with evidence of coil compaction. 
fetal pattern has the same caliber as the $\mathrm{P} 2$ segment of the posterior cerebral artery (PCA), and is associated with an atrophic $\mathrm{P} 1$ segment. Their incidence rates range from 4 to $29 \%$ for unilateral, and 1 to $9 \%$ for bilateral fetal PComA [10]. It was admittedly unusual that all of our PComA lesions exhibited this anatomical variation. This was not due to case selection bias, as we did not treat any other unruptured PComA lesions by other means during the study period.

PComA IAs are potentially difficult lesions to treat. In the International Subarachnoid Hemorrhage Trial (ISAT), PComA IAs treated endovascularly had a significantly higher recurrence rate [11]. On reviewing the outcome of coil-embolized PComAs, Songsaeng et al found five morphological factors that were predictive of initial aneurysm occlusion and long-term stability. They were small IA size, dome-to-neck ratio $<2$, small size of the PComA, ICA-fundus angle of 160 to 180 degrees, and posteroinferior dome orientation. Persistent fetal pattern was not studied as an individual factor [12]. For surgical clipping, lesions associated with fetal-type circulation may pose difficulties, in that backflow from a large PComA may persistently fill the IA even after a temporary clip was in place [10]. It is critical but not always possible to preserve adequate flow in these large PComAs during clipping. Zada et al described a patient who underwent clipping of an IA with fetal variant. The fetal-type PComA was sacrificed resulting in an occipital infarction [13].

In the context of treatment with the PED, all four of our fetal-type PComA IAs persisted and accounted for two-thirds of all failures. We surmised that while a PED placed within the ICA would protect the IA from ICA inflow, the dominant and large caliber fetal PComA will continuously sump blood from the ICA across the stent, resulting in diminished flow-diverting effect and therefore persistent aneurysm flow. Backflow from the PCA territory through the fetal-type PComA may also contribute to persistent aneurysm perfusion. On the other hand, in the presence of fetal PComA, increasing flow diversion by using multiple PED across the PComA ostium may jeopardize the perfusion to the PCA territory and may lead to ischemic complications. Therefore, based on our limited experiences, we do not find the PED a suitable treatment for PComA IAs with persistent fetal-type circulation, especially when an IA incorporates a significant portion of the PComA. Adjuvant coiling may help but can be technically difficult for a wideneck lesion located at bifurcations.

This study had several limitations. Our sample size was small which may have affected our statistical power. The use of multiple PEDs and adjuvant coiling in our treatment was not protocol-driven. Lastly, our follow-up period was relatively short.

\section{CONCLUSION}

Aneurysms located at persistent fetal-type PComA remain a therapeutic challenge. Incomplete occlusion was observed in all cases of PComA IAs associated with persistent fetal-type circulation treated with flow diverters. Our experience suggested that alternative or adjuvant modalities should be considered for this subgroup. Female patients were found to have a significantly higher rate of treatment success.

\section{Acknowledgement}

We thank Drs K.M. Leung, W.S. Ho, and K.K. Wong for their contributions in patient management.

\section{References}

1. Fiorella D, Kelly ME, Albuquerque FC, Nelson PK. Curative reconstruction of a giant midbasilar trunk aneurysm with the pipeline embolization device. Neurosurgery 2009;64:212-217

2. Fiorella D, Woo HH, Albuquerque FC, Nelson PK. Definitive reconstruction of circumferential, fusiform intracranial aneurysms with the pipeline embolization device. Neurosurgery 2008;62: 1115-1120

3. Lylyk P, Miranda C, Ceratto R, Ferrario A, Scrivano E, Luna HR, et al. Curative endovascular reconstruction of cerebral aneurysms with the pipeline embolization device: the Buenos Aires experience. Neurosurgery 2009; 64: 632-642

4. Leung GK, Tsang AC, Lui WM. Pipeline embolization device for intracranial aneurysm: a systematic review. Clin Neuroradiol 2012;22:295-303

5. Yu SC, Kwok CK, Cheng PW, Chan KY, Lau SS, Lui WM, et al. Intracranial aneurysms: midterm outcome of pipeline embolization device--a prospective study in 143 patients with 178 aneurysms. Radiology 2012;265: 893-901

6. Ryu CW, Kwon OK, Koh JS, Kim EJ. Analysis of aneurysm rupture in relation to the geometric indices: aspect ratio, volume, and volume-to-neck ratio. Neuroradiology 2011;53:883-889

7. McAuliffe W, Wycoco V, Rice H, Phatouros C, Singh TJ, Wenderoth J. Immediate and midterm results following treatment of unruptured intracranial aneurysms with the pipeline embolization device. AJNR Am J Neuroradiol 2012;33:164-670

8. Nelson PK, Lylyk P, Szikora I, Wetzel SG, Wanke I, Fiorella D. The pipeline embolization device for the intracranial treatment of aneurysms trial. AJNR Am J Neuroradiol 2011;32:34-40

9. O’Kelly CJ, Spears J, Chow M, Wong J, Boulton M, Weill A, et al. Canadian Experience with the Pipeline Embolization Device for Repair of Unruptured Intracranial Aneurysms. AJNR Am J Neuroradiol 2013;34:381-387

10. Golshani K, Ferrell A, Zomorodi A, Smith TP, Britz GW. A 


\section{Anderson Chun On Tsang, et al.}

review of the management of posterior communicating artery aneurysms in the modern era. Surg Neurol Int 2010;1:88

11. Campi A, Ramzi N, Molyneux AJ, Summers PE, Kerr RS, Sneade $\mathrm{E}$, et al. Retreatment of ruptured cerebral aneurysms in patients randomized by coiling or clipping in the International Subarachnoid Aneurysm Trial (ISAT). Stroke 2007;38:1538-1544

12. Songsaeng D, Geibprasert S, ter Brugge KG, Willinsky R, Tymianski M, Krings T. Impact of individual intracranial arterial aneurysm morphology on initial obliteration and recurrence rates of endovascular treatments: a multivariate analysis. J Neurosurg 2011;114:994-1002

13. Zada G, Breault J, Liu CY, Khalessi AA, Larsen DW, Teitelbaum GP, et al. Internal carotid artery aneurysms occurring at the origin of fetal variant posterior cerebral arteries. Neurosurgery 2008; 63:ONS55-ONS62 